\title{
Clinical Profile, Pattern of Presentation and Short Term Outcome of Cyanotic Congenital Heart Disease in Neonates
}

\author{
Dr. Dilruba Ibrahim Dipti ${ }^{1^{*}}$, Dr. Md. Abu Sayeed ${ }^{2}$, Dr. Abu Sayeed Munsi ${ }^{3}$
}

\author{
${ }^{1}$ Registrar, Cardiology unit, Dhaka Shishu (Children) Hospital, Dhaka, Bangladesh \\ ${ }^{2}$ Assistant Professor and Intensivist, Department of Pediatric Cardiology, Bangladesh Institute of Child Health and Dhaka Shishu (Children) Hospital, \\ Dhaka, Bangladesh \\ ${ }^{3}$ Associate Professor and Interventional Cardiologist, Department of Pediatric Cardiology, Bangladesh Institute of Child Health and Dhaka Shishu \\ (Children) Hospital, Dhaka, Bangladesh
}

DOI: $\underline{10.36347 / \mathrm{sjams} .2020 . v 08 \mathrm{i} 10.014}$

| Received: 04.10.2020 | Accepted: 15.10.2020 | Published: 17.10.2020

*Corresponding author: Dr. Dilruba Ibrahim Dipti

\section{Abstract}

Original Research Article

Background: Cyanotic heart disease refers to a group of many different heart defects that are present at birth (congenital) that results in a low blood oxygen level, many of which are life threatening in neonatal period necessitating early diagnosis and prompt treatment. Thus, by early intervention for critical cyanotic congenital heart diseases in neonatal period or early infancy, children can survive beyond the pediatric age. Aim of the study: To determine the clinical profile and pattern of presentation and short term outcome of cyanotic congenital heart disease in neonates. Methods and Materials: An observational type of cross-sectional study was conducted in the Department of Pediatric Cardiology of Dhaka Shishu hospital between the study period of July to December 2019 where total 74 newborn with cyanosis were recruited from outpatient and inpatient departments .Cyanotic congenital heart disease was diagnosed with the help of clinical examination and investigations finding and associated risk factor and treatment and short term outcome was documented. Results: Among the 74 neonates $58(78 \%)$ were male and 16(22\%) were female and male : female ratio was $3.6: 1$. Age of presentation of majority of patient $(n=36)$ was $16-28$ days whereas only 3 patient presented in between 0-2 days. The neonates mainly had Transposition of Great Arteries (TGA) (n=22), Tetralogy of Fallot (TOF) $(n=12)$,Tricuspid Atresia(n=7), DORV(n=7), Total Anomalous Pulmonary Venous Return( $(n=5)$, Hypoplastic Left Heart Syndrome( $n=3)$. The median age of presentation of common cyanotic congenital heart defects like TGA, TOF, Tricuspid Atresia, DORV are 12-15 days. Median age of presentation for TAPVC was highest that is 23 days and Ebstein anomaly was lowest that is 8 days. In this study all of the study neonates $(\mathrm{n}=74)$ had cyanosis. Out of 74 patient $69(93 \%)$ had tacyhpnea, 61(82\%) had tachycardia, 38(51\%) had murmur, 26(35\%) had hepatomegaly. Crepitation, rhonchi and oedema were found respectively 34(45\%), 24(32\%) and 19(25\%) patients. 2 patient $(2.7 \%)$ presented with shock. In this study it has been seen that majority of the patient that is $54(72 \%)$ were term neonate. Family history of CHD were found in $9(12 \%)$ of patient and consanguinity was found in 31 (41\%) of patient. Other risk factors found were maternal diabetes mellitus in 19 (26\%) patients, maternal hypertension in 28 (37\%) patients, infection during pregnancy in $15(20 \%)$ patient and parental smoking in $39(53 \%)$ patients In this study $9(12 \%)$ patient received prostaglandin, 21 (28\%) required use of Ionotrops, antifailure drugs were used in $36(48 \%)$ patients and emergency procedures were performed in $13(17 \%)$ patients. Regarding outcome, 11 (14\%) patient required ventilatory support, $19(25 \%)$ had an ICU stay and death occurred in $6(8 \%)$ patients. Conclusion: Cyanotic congenital heart disease in neonates is often undiagnosed which is main the cause of high case fatality. Development of neonatal screening program for early detection of such cases and prompt measure can surely save life of many newborns. Therefore gathering knowledge about the clinical profile and pattern of presentation of cyanotic congenital heartdisease in neonates in our country's perspective will definitely help to avoid complication, reduce mortality and improve quality of life of the newborns.

Keywords: Cyanotic congenital heart disease, neonates, clinical profile, outcome.

Copyright $(\mathcal{2 0 2 0}$ The Author(s): This is an open-access article distributed under the terms of the Creative Commons Attribution 4.0 International License (CC BY-NC 4.0) which permits unrestricted use, distribution, and reproduction in any medium for non-commercial use provided the original author and source are credited.

\section{INTRODUCTION}

Congenital heart disease (CHD) is the most common congenital problem in children .In order to avoid complications, reduce mortality and for proper management early detection of congenital heart disease is of utmost importance [1]. Congenital heart diseases are mainly grouped as Acyanotic and Cyanotic. Acyanotic heart disease includes: Ventricular septal 
defect, Atrial septal defect (ASD), Patent ductus arterious (PDA), Coarctation of aorta (COA) and Aortic stenosis (AS). Cyanotic heart disease includes Tetralogy of fallot (TOF), Transposition of the great vessels (TGA), Total Anomalies pulmonary versus return (TAPVR), Pulmonary atresia, Hypoplastic left heart syndrome etc [2]. Cyanotic congenital heart diseases are critical congenital heart disease, that cause serious and often life threatening symptoms and accounts for more deaths than any other type of congenital malformation $[3,4]$. Nearly 4,800 babies born each year in the United States have CCHD, and nearly 280 infants with unrecognized CCHD are discharged annually [4]. CCHDs often go undetected because some babies will appear healthy at first and are discharged from the hospital before any defect is detected However, due to the severity of these conditions, immediate follow up to determine the best method of treatment or intervention is necessary. CCHD is associated with hypoxemia (insufficient levels of oxygen in the blood or tissues) and among infants during the newborn period, hypoxemia represents 17-31 percent of all CHDs [5, 6]. The primary targets of CCHD screening include: Hypoplastic left heart syndrome, Pulmonary atresia (with intact ventricular septum), Tetralogy of Fallot, Total anomalous pulmonary venous return, Transposition of the great arteries, Tricuspid atresia, and Truncus arteriosus. Infants with these conditions require surgical or catheter intervention within the first few days or first year of life. Without early diagnosis or treatment, infants with CCHDs are at significant risk of morbidity or mortality due to physiological changes of the heart (e.g, closing of the Ductus arteriosus) [8]. In the United States an estimated 4,800 babies born each year have CCHD, and nearly 280 of those infants may be missed by routine newborn cardiac screening [9]. Prenatal ultrasound has been used for many years in advanced countries for screening of congenital abnormalities and plays an important role in identifying CCHD but this scenario is quite different in a developing country like Bangladesh [10]. This is especially true for critical congenital heart disease, a group of morphologically heterogeneous disorders which have in common that early surgical or catheter interventional therapy is mandatory to achieve survival. Clinical examination is unable to detect all forms of CHD [11]. Heart murmurs, one of the hallmarks of noncritical heart disease typically diagnosed later in the life may be absent or misleading in CCHD because of the underlying anatomy, prolonged decline of pulmonary vascular resistance or reduced ventricular function. Despite of the increasing number of prenatal and postnatal diagnostic facility, a significant proportion of the affected newborns are still not diagnosed as the stay at home after home delivery in Bangladesh or not detected before discharge after birth in case of health facility delivery [12]. The first manifestation of CCHD may be acute due circulatory collapse and need cardiopulmonary resuscitation or death occurs if delay in diagnosis. So this condition is associated with significant morbidity and mortality $[13,14]$. The current incidence of this severe physiologic compromise resulting from previously unrecognized CCHD has been estimated to be 1 per 15,000 to 1 per 26,000 live birth. Hence, there is broad consensus that screening for CCHD is warranted [15]. Cyanotic heart disease refers to a group of many different heart defects that are present at birth (congenital) that results in a low blood oxygen level. There are many physical defects in the heart that can cause cyanotic congenital heart disease. Many cases of CHD attend Pediatric OPD as well as in patient department of Dhaka Shishu Hospital but data regarding relative frequency, pattern, age and sex distribution of CHD are very scanty from this region. Although cyanotic congenital heart disease accounts for less than $25 \%$ of cardiac defects, many of these are life threatening in neonatal period, thereby necessitating early diagnosis and prompt treatment. Availability of diagnostic tools like echocardiography, fetal scanning, advancement in surgical techniques and postoperative care can radically improve the life expectancy of affected children. Thus, by early intervention for critical cyanotic congenital heart diseases in neonatal period or early infancy, children are now surviving beyond the pediatric age. This study will help us to determine the relative frequency, predisposing risk factors and gravity of critical cyanotic cardiac lesions presenting in neonatal period. The findings will hopefully have implications in development of cardiac service in other tertiary care centers.

\section{OBJECTIVES \\ General Objective}

- To determine the clinical profile and pattern of presentation of cyanotic congenital heart disease in neonates.

\section{Specific Objectives}

- To determine the clinical profile of cyanotic congenital heart disease in neonates.

- To determine the pattern of cyanotic congenital heart disease in neonates.

- To determine the short term outcome of cyanotic congenital heart disease in neonates.

\section{Methodology ANd Materials}

This study was designed as a cross sectional study which was carried out from $1^{\text {st }}$ July 2019 to $31^{\text {st }}$ December 2019 in Dhaka Shishu (Children) hospital. Dhaka Shishu (Children) Hospital (Total bed 650) has both paediatric medicine and surgery unit. A large number of patients is admitted over there each day due to various complaints and modern laboratory facilities also available for their proper diagnosis and treatment by skilled doctors and other health professional. Patients were seen in outpatient department or admitted in inpatient department of Dhaka Shishu Hospital from July to December 2019 where neonates presenting with various systemic complaints or significant cyanosis. 


\section{Inclusion Criteria}

- Children admitted between age 0-28 days with cyanotic congenital heart disease in the outdoor \& indoor patients department of Pediatric and Cardiology, DSH.

- Both sexes

\section{Exclusion Criteria}

- Patients/legal guardians who would not give consent

- Old/cases already evaluated by echocardiography

- $\quad$ Age $>28$ days

- Unstable patients who died before the confirmation of diagnosis.

Among the 0-28 days' neonates with clinical features of chest infection, respiratory distress, cyanosis or cyanotic spells, poor feeding or difficulty in feeding $\&$ other relevant history and clinical findings of critical cyanotic congenital heart disease in Dhaka shishu (children) hospital. The study included neonates of both male and female. For each baby detailed history of age, sex, parental age, family history, onset of cyanosis and preceding/existing symptoms were recorded. A thorough general examination and other systemic examinations were done. A chest $\mathrm{X}$ ray, ECG and echocardiography were routinely done in all patients and if needed other investigation were performed depending upon the clinical presentation. Chest X-ray was done by professional Radiologists and echocardiography by Pediatric Cardiologists of the study places. Clinical profile and interpretations of other investigation findings were then correlated with echo cardio graphic findings. Prior to the commencement of this study ethical permission was taken from ethical review committee of Bangladesh Institute of Child Health, Dhaka Shishu (Children) Hospital. The aim and objectives of the study along with its procedure was explained to the child's parents in easily understandable local language and informed consent was taken from each guardian. It was assured that all the information and records would be kept confidential and the procedure would be helpful for both patients and physicians in making rational approach of the case management. All the data were collected and recorded systematically in a questionnaire and were analyzed manually.

\section{RESULTS}

In this study out of 74 neonates with cyanotic congenital heart disease $78 \%(n=58)$ were male and $22 \%(n=16)$ were female. Male: Female ratio was 3.6:1 (Figure-1). In this study majority of patient that is 36 neonates presented in between age of 16-28 days of age (48\%). 21 patient presented at age range of 3-7 days (28\%), 14 patient presented in between $8-15$ days of age (18\%) and only 3 neonates presented at 0-2 days (4\%) (Figure-2). This table shows out of 74 neonates 22 (29\%) were diagnosed of having Transposition of Great Arteries (TGA). Tetralogy of Fallot (TOF) were found in 12 neonates (16\%), Pulmonary Atresis, DORV, Tricuspid Atresia were found in 7 patients (9.4\%) respectively. Other cyanotic heart diseases observed were Total Anomalous Pulmonary Venous Return, Truncus Arteriosus, Hypoplastic Left Heart Syndrome etc (Table-1). In this study all of the study neonates $(n=74)$ had cyanosis. Out of 74 patients $69(93 \%)$ had tacyhpnea, 61(82\%) had tachycardia, 38(51\%) had murmur, 26(35\%) had hepatomegaly. Crepitation, rhonchi and oedema were found respectively $34(45 \%)$, $24(32 \%)$ and $19(25 \%)$ patients. 2 patients $(2.7 \%)$ presented with shock (Figure-3). This study reveals median age of presentation for Transposition of great arteries, Tricuspid atresia and Double outlet right ventricle were 15 days. Median age of presentation for TAPVC was highest that is 23 days and Ebstein anomaly was lowest that is 8 days (Table-2). Chest Xray findings were oligaemic lung in $39 \%$, plethoric lung in $44 \%$, cardiomegaly in $46 \%$, egg on side shaped heart in $14 \%$ patients and boot shaped heart was found in $5 \%$ patients (Table-3). In this study it has been seen that majority of the patient that is $54(72 \%)$ were term neonate. Family history of CHD were found in $9(12 \%)$ of patient and consanguinity was found in $31(41 \%)$ of patient. Other risk factors found were maternal diabetes mellitus in 19 (26\%) patients, maternal hypertension in $28(37 \%)$ patients, infection during pregnancy in 15 (20\%) patient and parental smoking in $39(53 \%)$ patients (Table-4). In this study $9(12 \%)$ patient received prostaglandin, $21(28 \%)$ required use of Ionotrops, antifailure drugs were used in 36 (48\%) patients and emergency procedures were performed in 13 (17\%) patients. Regarding outcome, 11 (14\%) patient required ventilatory support, $19(25 \%)$ had an ICU stay and death occurred in $6(8 \%)$ patients (Table$5)$. 


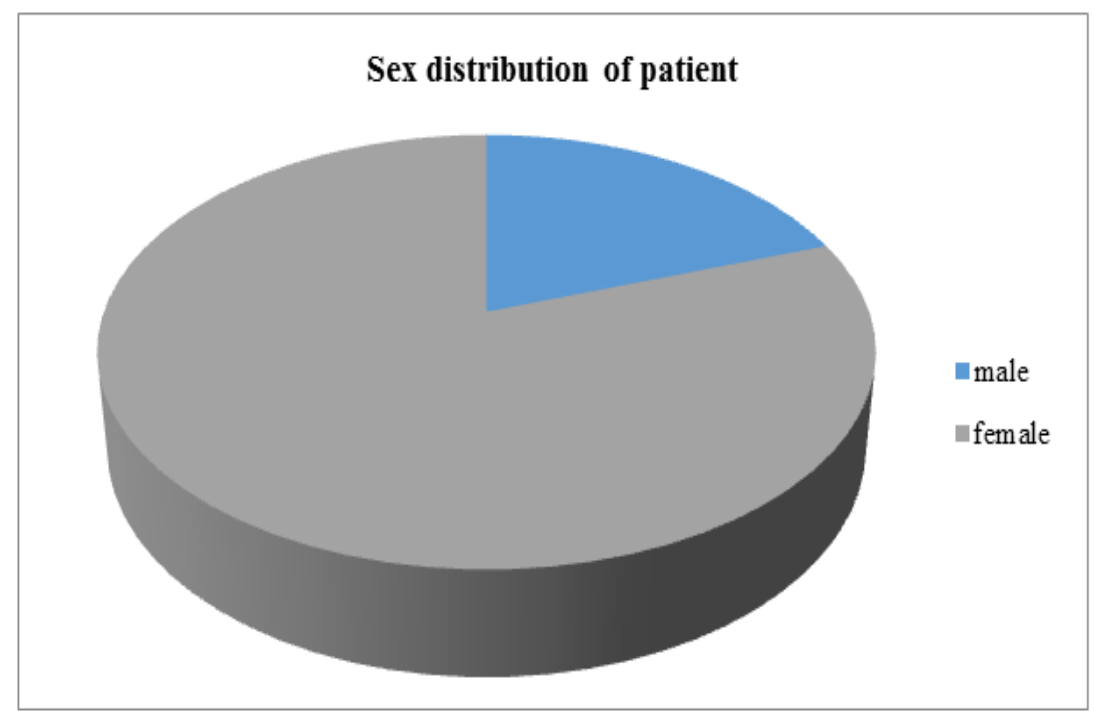

Fig-1: Sex distribution of neonates with cyanotic heart disease

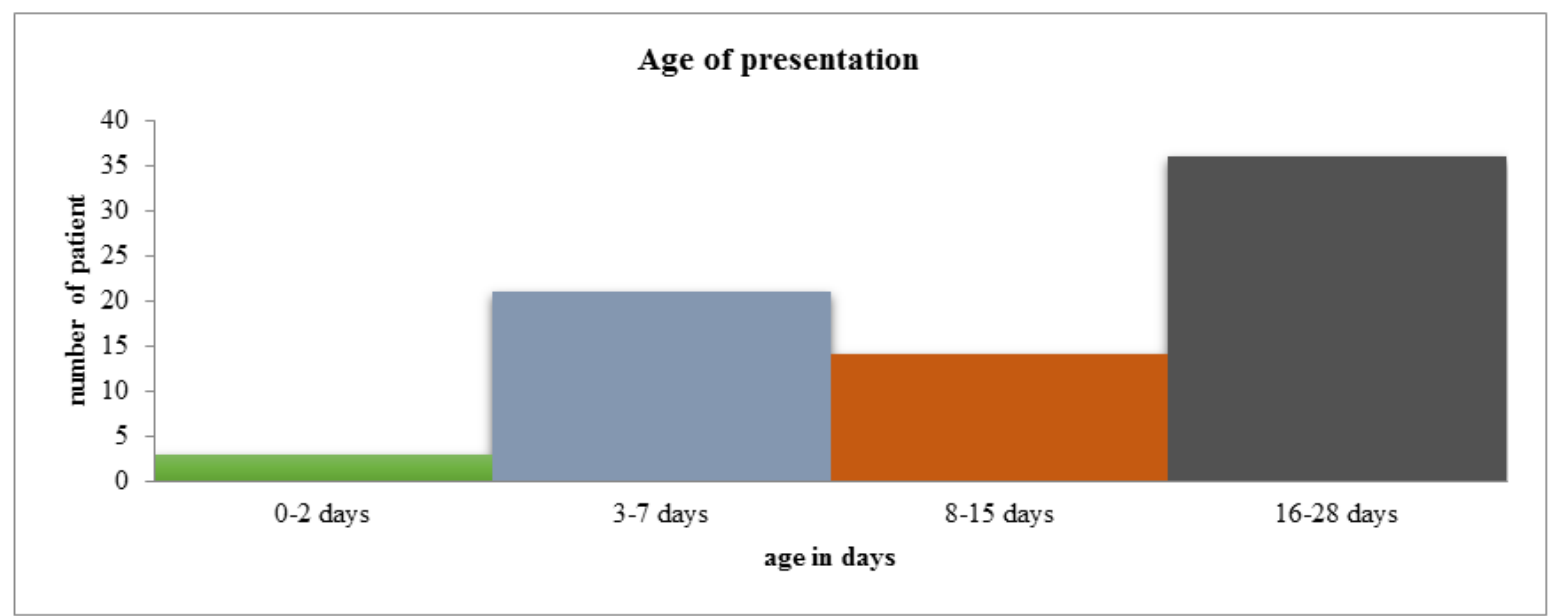

Fig-2: Frequency distribution of patient according to age of presentation

Table-1: Types of cyanotic congenital heart disease among study neonates $(\mathrm{N}=74)$

\begin{tabular}{|l|l|l|l|l|}
\hline Type of cyanotic heart disease & Number of total patient & Percentage & Male & Female \\
\hline Transposition of great arteries (TGA) & 22 & $29 \%$ & 20 & 2 \\
\hline Tetralogy of fallot (TOF) & 12 & $16 \%$ & 6 & 6 \\
\hline Tricuspid atresia & 7 & $9.4 \%$ & 5 & 2 \\
\hline Double outlet right ventricle (DORV) & 7 & $9.4 \%$ & 4 & 3 \\
\hline DORV with Pulmonary atresia & 2 & $2.7 \%$ & 2 & 0 \\
\hline Pulmonary atresia & 7 & $9.4 \%$ & 5 & 2 \\
\hline Total anomalous pulmonary venus return (TAPVC) & 5 & $6.7 \%$ & 3 & 5 \\
\hline Hypoplastic left heart syndrome (HLHS) & 3 & $4 \%$ & 2 & 1 \\
\hline Truncua arteriosus & 2 & $2.7 \%$ & 2 & 0 \\
\hline Single ventricle & 2 & $2.7 \%$ & 2 & 0 \\
\hline Ebstein anomaly & 2 & $2.7 \%$ & 0 & 2 \\
\hline Mitral atresia with double inlet left ventricle & 2 & $2.7 \%$ & 2 & 0 \\
\hline Critical pulmonary stenosis & 1 & $1.3 \%$ & 0 & 1 \\
\hline
\end{tabular}




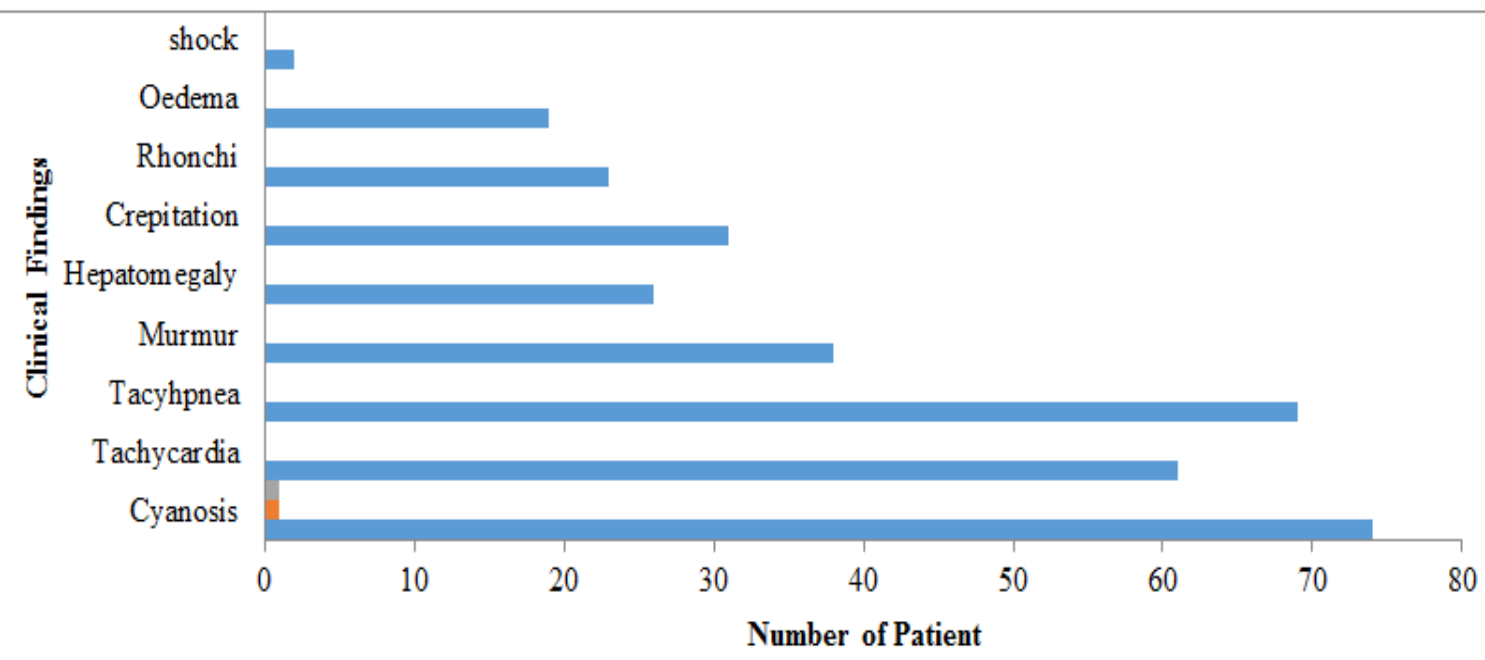

Fig-3: Clinical findings of the neonates with cyanotic congenital heart disease

Table-2: Median age of presentation of cyanotic congenital heart diseases

\begin{tabular}{|l|l|}
\hline Types of cyanotic heart disease & Median age of presentation \\
\hline Transposition of great arteries (TGA) & 15 days \\
\hline Tetralogy of fallot (TOF) & 14 days \\
\hline Tricuspid atresia & 15 days \\
\hline Double outlet right ventricle (DORV) & 15 days \\
\hline DORV with Pulmonary atresia & 18 days \\
\hline Pulmonary atresia & 19 days \\
\hline Total anomalous pulmonary venus return (TAPVC) & 23 days \\
\hline Hypoplastic left heart syndrome (HLHS) & 10 days \\
\hline Truncua arteriosus & 19 days \\
\hline Single ventricle & 21 days \\
\hline Ebstein anomaly & 8 days \\
\hline
\end{tabular}

Table-3: Chest $X$-ray findings among the study patients $(n=74)$

\begin{tabular}{|l|l|l|}
\hline X-ray finding & Number of patient & Percentage \\
\hline Oligaemic lung & 29 & $39 \%$ \\
\hline Plethoric lung & 33 & $44 \%$ \\
\hline Cardiomegaly & 34 & $46 \%$ \\
\hline Egg on side appearance of heart & 11 & $14 \%$ \\
\hline Boot shaped heart & 4 & $5 \%$ \\
\hline Figure of 8 shaped heart & 1 & $1.3 \%$ \\
\hline
\end{tabular}

Table-4: Baseline demographic characteristics of study patient ( $n=74)$

\begin{tabular}{|l|l|}
\hline Variable & Number (\%) \\
\hline Gestational age: Term & $54(72 \%)$ \\
\hline Preterm & $20(27 \%)$ \\
\hline Family history of CHD & $9(12 \%)$ \\
\hline Consanguinity & $31(41 \%)$ \\
\hline Maternal diabetes mellitus & $19(26 \%)$ \\
\hline Maternal hypertension & $28(37 \%)$ \\
\hline Infection during pregnancy & $15(20 \%)$ \\
\hline Exposer to teratogenic drugs & $2(2.7 \%)$ \\
\hline Parental smoking & $39(53 \%)$ \\
\hline
\end{tabular}


Table-5: Treatment required and outcome of study patient

\begin{tabular}{|l|l|}
\hline Variable & Number (\%) \\
\hline Received prostaglandin & $9(12 \%)$ \\
\hline Required use of Ionotrops & $21(28 \%)$ \\
\hline Use of anti-failure drugs (frucemide, digoxin) & $36(48 \%)$ \\
\hline Ventilatory support & $11(14 \%)$ \\
\hline Emergency procedures & $13(17 \%)$ \\
\hline Required ICU stay & $19(25 \%)$ \\
\hline Death & $6(8 \%)$ \\
\hline
\end{tabular}

\section{DISCUSSION}

This study was done to see the clinical profile, pattern and frequency of presentation of cyanotic congenital heart disease in neonates. Total 74 neonates were diagnosed as cases having cyanotic congenital heart disease during the study period of July to December 2019 on the basis of inclusion criteria.In this study out of 74 neonates with cyanotic congenital heart disease $78 \%(n=58)$ were male and $22 \%(n=16)$ were female. Male: Female ratio was 3.6: 1 . In a study by Mahapatra A et al., where among 231 patients with CHD, CHD were more common among males (54.5\%) with the male to female ratio is $1.2: 1$ [33]. In this study majority of patient that is 36 neonates presented in between age of 16-28 days of age (48\%). 21 patient presented at age range of 3-7 days (28\%), 14 patient presented in between $8-15$ days of age $(18 \%)$ and only 3 neonates presented at $0-2$ days (4\%). Out of 74 neonates $22(29 \%)$ were diagnosed of having Transposition of Great Arteries (TGA). Tetralogy of Fallot (TOF) were found in 12 neonates (16\%), Pulmonary Atresis, DORV, Tricuspid Atresia were found in 7 patients (9.4\%) respectively. Other cyanotic heart diseases observed were Total Anomalous Pulmonary Venous Return, Truncus Arteriosus, Hypoplastic Left Heart Syndrome etc. A study conducted by Tsao P-C et al. where pulse oxymetric screening could detect 5 cyanotic congenital defects in neonates and among them 2 cases were TGA, 1 of HLHS, 1 case of Ebstein anomaly and 1 case of DORV with single ventricle [34]. In another study by Nadia M et al., out of 150 study patient cyanotic lesions tetralogy of Fallot (TOF) was the commonest lesion found in $11.2 \%$ of the patients, this number was higher as compared to international data $[35,36]$. However recent study of Agha Khan University, reported an even higher percentage of $25 \%$ [37]. In this study, the second common cyanotic lesion was TGA seen in $5.2 \%$, this is in accordance with study at Atlanta ${ }^{38}$ but contrast with study of Taiwan in which TGA was twice commonthan TOF. ${ }^{35}$ Dextrocardia was seen in $1.5 \%$ (2 cases) presented in neonatal period [39]. This study reveals median age of presentation for Transposition of great arteries, Tricuspid atresia and Double outlet right ventricle were 15 days. Median age of presentation for TAPVC was highest that is 23 days and Ebstein anomaly was lowest that is 8 days. A study by Colaco $\mathrm{S}$ et al., where among the 71 newborn with critical congenital heart disease, median age at diagnosis was
10 days and median age of presentation was 13.5 days [40]. In this study all of the study neonates $(n=74)$ had cyanosis. Out of 74 patients $69(93 \%)$ had tacyhpnea, $61(82 \%)$ had tachycardia, $38(51 \%)$ had murmur, $26(35 \%)$ had hepatomegaly. Crepitation, rhonchi and oedema were found respectively 34(45\%), 24(32\%) and $19(25 \%)$ patients. 2 patients $(2.7 \%)$ presented with shock. Mahapatra A et al., showed out of 231 of his study patients 196 had murmurs, 96 had tachycardia, 84 had tacyhpnea, 28 had clubbing, 21 had oedema, 41 had enlarged liver [33]. Chest X-ray findings were oligaemic lung in $39 \%$, plethoric lung in $44 \%$, cardiomegaly in $46 \%$, egg on side shaped heart in $14 \%$ patients and boot shaped heart was found in 5\% patients. In this study it has been seen that majority of the patient that is $54(72 \%)$ were term neonate. Family history of CHD were found in $9(12 \%)$ of patient and consanguinity was found in $31(41 \%)$ of patient. Other risk factors found were maternal diabetes mellitus in 19 (26\%) patients, maternal hypertension in $28(37 \%)$ patients, infection during pregnancy in $15(20 \%)$ patient and parental smoking in 39 (53\%) patients. Vaidyanathan B et al., demonstrated in his study where among 5487 newborns 4950 were term, 107 patient had consanguinity, 542 neonates mother had diabetes, maternal hypertension was present in 571 patient and maternal infection during pregnancy was found in 264 patients [41]. In this study $9(12 \%)$ patient received prostaglandin, $21(28 \%)$ required use of Ionotrops, antifailure drugs were used in $36(48 \%)$ patients and emergency procedures were performed in $13(17 \%)$ patients. Regarding outcome, 11 (14\%) patient required ventilatory support, 19 (25\%) had an ICU stay and death occurred in $6(8 \%)$ patients. A study conducted by Colaco S et al., where comparison of neonates with cyanotic HD diagnosed antenataly and postnataly was done. Among the postnataly group out of 71 patient 19 were transferred on prostin, 4 patient required ionotrops, 9 patient had convulsion and 4 patient died [40].

\section{Limitations OF THE STUDY}

A limitation of this study is the relatively small sample size and study period was short. For evaluation of consequence of cyanotic congenital heart disease in neonates all facilities were not available in the place of study. Echocardiography was expensive and many poor patients couldn't afford to do that. Lowering the cost of investigation would be beneficial for the patients. 


\section{CONCLUSION AND}

\section{RECOMMENDATIONS}

Cyanotic congenital heart disease in neonates is often undiagnosed which is main the cause of high case fatality. Development of neonatal screening program for early detection of such cases and prompt measure can surely save life of many newborns. Therefore, gathering knowledge about the clinical profile and pattern of presentation of cyanotic congenital heart disease in neonates in our country's perspective will definitely help to avoid complication, reduce mortality and improve quality of life of the newborns. Pediatric echocardiography as diagnostic tool should be made more widely available especially in tertiary institutions to enable early diagnosis and, screening for possible cardiac defects during pregnancy. There is an urgent need for the government to establish pediatric cardiac surgical centers with specialized medical cardiology, intensive care, imaging and interventions. All newborn babies should be examined thoroughly for any evidence of CHD by pediatrician before hospital discharge and on follow up visits in the early neonatal period. There is a need to intensify efforts to educate general practitioner and other health professionals who come across children with heart disease, as they are the ones who can screen, diagnose and refer these babies to cardiac facility and the earlier the diagnosis, the easier it would be to do timely management in appropriate manner.

\section{REFERENCES}

1. Hussain M. Tahura S. Sayeed MA. Rahman MM. Rahman MM Kar SK Past and Present Pattern of Congenital Heart Disease at Dhaka Shishu Hospital: A Situation Analysis Bangladesh J Child health. 2010;34(2):51-55

2. Tambulwalkar RS. Paediatric Nursing $2^{\text {nd }}$ ed. Mumbai Vora Medical Publication, 2001.

3. Heron MP, Smith BL. Deaths leading causes for 2003, Natt Vital Stat Rep. 2007; 55:1-92 available at htt//www.ncbi.nlm.nih.gov/pubmed/17408087 Accessed 6-28-20131.

4. Rosano A, Botto LD, Botting B, Mastroiacovo P. Infant mortality and congenital anomalies from 1950 to 1994: an international perspective. Journal of Epidemiology \& Community Health. 2000 Sep 1;54(9):660-6. Available at http//jech.bmj. com/ content/ 54/9/660 full pdf Accessed 6-28-2013

5. Knall AA, Metterville DR, Kemper AR. Evidence review Critical congenital cyanotic heart disease. Available

at http//www.hrsagov/advisorycommittees/mchbadvis ory/heritab/edisorders/nomin tecondition/reviews/cyanoticheart.pdf. Accessed 86-2012

6. CDC "Screening for Critical Congenital Heart defects" Available at Htt//www.cdc gov/ncbddd/pediatricgenetics/pulse html/ Accessed 5-10-2013

7. Knapp AA, Mattervile DR, Kemper AR. Evidence review Critical congenital cyanotic heart disease. Available at http//www.hrsa gov/advisorycommittees/mchbadvisory/heritable disorders/nomi atecondition/ reviews/ cyanotic heart. pdf. Accessed 8-6-2012

8. Talner CN. "Report of the New England regular Infant Cardiac program by Donald C Flyer, MD, Pediatrics 1980,65 (suppl) 375-461. "Pediatrics 1998, 102 (pt 2) 258-259 Available athttp//www. Ncbi nlm gov/ Pubmed/9651450 Accedd 6-282013

9. Knapp AA, Metterville DR, Kemper AR, Prosser L, Perrin JM. Evidence review: Critical congenital cyanotic heart disease. US Department of Health and Human Services [DHHS], Health Resources and Services Administration, Maternal and Child Health. 2010. Available http//www.hrsa.gov/advisorycommittees/mchbadvi sory/herdabledisorders/nominate

condition/reviewscyanoticheart.pdf. Accessed 8-62012

10. Bofill JA Sharp GH. Obstetric sonography who to scan when to scan and by whom. Obstet gynecol Clin North Am. 1998; 25: 465-478. Available at http//www.ricbi nim nih. Gov/pubmed/9710906. Accessed 6-28-2013

11. Ainsworth S, Wyllie JP, When C. Prevalence and clinical significance of cardiac murmurs in neonates. Arch Dis Child fetal neonatal Ed. 1999; 80:F43-F45

12. Chang RK, Roodriguez S, Klitzner TS (2009) Screening newborns for congenital heart disease with pulse oximetry survey of pediatric cardiologists pediatr Cardiol 30;20-25

13. Brown KL, Ridout DA, Hoskote A, Verhulist L, Ricci M, Bull C. Delayed diagnosis of congenital heart disease worsers preoperative condition and outcome of surgery in neonates Heart. 2006; 92:1298-1302.

14. Chang RK, Gurvitz M, Rodriguez S. Missed diagnosis of critical congenital heart disease. Arch pediatr Adolesc med. 2008; 162; 969-974.

15. Mahle WT, Newburger JW, Matheme GP, Smith FC, Hoke TR, Koppel R, Gidding SS, Beekman RH $3^{\text {rd }}$, Gross SD (2009) Role of pulse oximetry inexamining newborns for congenital heart disease a scientific statement from the AHA and AAP. Pediatrics 124: 823-836.

16. Mann Z, Libby B (Editors). Braunwalds Heart Disease, A textbook of cardiovascular medicine, 10th Edition. Published by Reed Elsevier India private limited, 1391-1392.

17. Chang RK, Gurvitz M, Rodriguez S. Missed diagnosis of critical congenital heart disease. Arch Pediatr Adolesc Med. 2008; 162:969-74.

18. Yee L. Cardiac emergencies in the first year of life. Emerg Med Clin North Am. 2007; 25:981-1008. 
19. Friedman AH, Fahey JT. The transition from fetal to neonatal circulation: normal responses and implications for infants with heart disease. Semin Perinatol, 1993; 17:106-21.

20. Hoffman JI. It is time for routine neonatal screening by pulse oximetry. Neonatology. 2011; 99:1.

21. Schultz AH, Localio AR, Clark BJ, Ravishankar C, Videon N, Kimmel SE. Epidemiologic features of the presentation of critical congenital heart disease: implications for screening. Pediatrics. $2008 \mathrm{Apr}$ 1;121(4):751-7.

22. Chang RK, Gurvitz M, Rodriguez S. Missed diagnosis of critical congenital heart disease. Arch Pediatr Adolesc Med. 2008; 162:969

23. Danford DA, McNamara DG. Infants with congenital heartdisease in the first year of life. In: The Science and Practice of Pediatric Cardiology, Garson A, Bricker JT, Fisher SR (Eds), Williams \& Wilkins, Baltimore. 1998. p.2228

24. Pickert CB, Moss MM, Fiser DH. Differentiation of systemic infection and congenital obstructive left heart disease in the very young infant. Pediatr Emerg Care. 1998; 14:263

25. Yabek SM. Neonatal cyanosis. Reappraisal of response to100\% oxygen breathing. Am J Dis Child. 1984; 138:880.

26. Duff, FD, McNamara, DG. History and physical examination of the cardiovascular system. In: The Science and Practice of Pediatric Cardiology, Garson A, Bricker JT, Fisher DJ, Neish SR (Eds), Williams and Wilkins, Baltimore 1998. p.693

27. Rowe RD, Izukawa T, Olley PM, Freedom RM, Swyer PR. Abnormalities of the cardiovascular transition of the newborn: current views on vascular and myocardial responses. Pediatric Cardiology, Godman MJ (Ed), Churchill Livingstone, New York. 1981.

28. Pierpont ME, Basson CT, Benson Jr DW, Gelb BD, Giglia TM, Goldmuntz E, McGee G, Sable CA, Srivastava D, Webb CL. Genetic basis for congenital heart defects: current knowledge: a scientific statement from the American Heart Association Congenital Cardiac Defects Committee, Council on Cardiovascular Disease in the Young: endorsed by the American Academy of Pediatrics. Circulation. 2007 Jun 12;115(23):301538.

29. Hartman RJ, Rasmussen SA, Botto LD, RiehleColarusso T, Martin CL, Cragan JD, Shin M, Correa A. The contribution of chromosomal abnormalities to congenital heart defects: a population-based study. Pediatric cardiology. 2011 Dec 1;32(8):1147-57.
30. Øyen N, Poulsen G, Boyd HA, Wohlfahrt J, Jensen PK, Melbye M. Recurrence of congenital heart defects in families. Circulation. 2009 Jul;120(4):295-301.

31. Talner CN. Report of the New England Regional Infant Cardiac Program, by Donald C. Fyler, MD, Pediatrics, 1980; 65(suppl):375-461. Pediatrics 1998; 102:258.

32. Wren C, Reinhardt Z, Khawaja K. Twenty-year trends in diagnosis of life-threatening neonatal cardiovascular malformations. Arch Dis Child Fetal Neonatal Ed. 2008; 93:F33

33. Mahapatra A, Sarangi R, Mahapatra PP. Spectrum of congenital heart disease in a tertiary care centre of Eastern India. Int J Contemp Pediatr. 2017 Mar;4(2):314-6.

34. Tsao PC, Shiau YS, Chiang SH, Ho HC, Liu YL, Chung YF, Lin LJ, Chen MR, Chang JK, Soong WJ, Lin HL. Development of a newborn screening program for critical congenital heart disease (CCHD) in Taipei. PLoS One. 2016 Apr 13;11(4):e0153407.

35. Misra M, Mittal M, Verma AM, Rai R, Chandra G, Singh DP, Chauhan R, Chowdhary V, Singh RP, Mall AK, Khan MJ. Prevalence and pattern of congenital heart disease in school children of eastern Uttar Pradesh. Indian heart journal. 2009;61(1):58-60.

36. Yu CH, Lue HC, Wu SJ, Chen MR. Heart disease screening of school children in Taiwan. Arch Pediatr Adolesc Med. 2009;163:233e237.

37. Humayun KN, Atiq M. Clinical profile and outcome of cyanotic congenital heart disease in neonates. J Coll Physicians Surg Pak. 2008;18:290e293.

38. Reller MD, Strickland MJ, Colarusso TR, Mahle WT, Correa A. Prevalence of congenital heart defects in Metropolitan Atlanta, 1998e2005. J Pediatr. 2008;153:807e813.

39. Mohammad N, Shaikh S, Memon S, Das $H$. Spectrum of heart disease in children under 5 years of age at Liaquat University Hospital, Hyderabad, Pakistan. Indian heart journal. 2014 Jan $1 ; 66(1): 145-9$.

40. Colaco SM, Karande T, Bobhate PR, Jiyani R, Rao SG, Kulkarni S. Neonates with critical congenital heart defects: Impact of fetal diagnosis on immediate and short-term outcomes. Ann Pediatr Card 2017;10:126-30.

41. Vaidyanathan B, Sathish G, Mohanan ST, Sundaram KR, Warrier KK, Kumar RK. Clinical screening for congenital heart disease at birth: a prospective study in a community hospital in Kerala. Indian pediatrics. 2011 Jan 1;48(1):25-30. 